\title{
Efeito de óleos essenciais sobre o fungo Thielaviopsis paradoxa
}

\author{
Effect of essential oils on the fungus Thielaviopsis paradoxa
}

\author{
Matheus Nunes Pereira ${ }^{1}$ \\ Rafael Batista da Conceição ${ }^{2}$ \\ Juliana Cristina Sodário $\mathrm{Cruz}^{3}$ \\ Meire Cristina Nogueira de Andrade $\left.{ }^{4}{ }^{*}\right)$
}

\section{Resumo}

A cana-de-açúcar atualmente tem um papel fundamental na economia do país. Entretanto, os canaviais estão expostos a riscos de contaminação por fungos, entre eles, o Thielaviopsis paradoxa, patógeno causador da podridão do abacaxi. Entre os possíveis métodos de controle dessa doença, estão os óleos essenciais, os quais são substâncias voláteis, geralmente líquidas e odoríferas, extraídas do metabolismo secundário de vegetais que podem ser usados como antifúngicos, inseticidas e antibactericidas. Assim, o objetivo do presente estudo foi testar o efeito de óleos essenciais no controle de $T$. paradoxa, possibilitando, assim, um tratamento que não cause danos à saúde, tanto de quem trabalha nos canaviais, quanto de quem irá consumir o alimento depois de pronto, que seja mais econômico e simples de se obter. $\mathrm{O}$ experimento conduzido foi no delineamento inteiramente casualizado segundo o esquema fatorial 4 × 3 (4 tipos de óleos essenciais x 3 concentrações) com 4 repetições. Também foi conduzida juntamente com os tratamentos duas testemunhas (meio de cultura BDA sem adição de óleo essencial e com adição do fungicida Piraclostrobina, cada qual com 4 repetições), totalizando 56 unidades experimentais. Foram testados os seguintes óleos essenciais no crescimento micelial in vitro do fungo T.paradoxa: Cravo folha (Eugenea caryophyllus), Hortelã Pimenta (Mentha piperita), Capim-limão (Cymbopogon citratus), Manjericão (Ocimum basilicun), nas concentrações $0,25 \%, 0,50 \%$ e 0,75\%. Os óleos essenciais de Hortelã pimenta, Capim limão e Manjericão inibiram em 100\% o crescimento micelial em todas as concentrações testadas, sendo tão eficientes quanto ao fungicida Piraclostrobina que, geralmente, é utilizado no combate ao fungo. O tratamento com o Cravo folha também inibiu bem o crescimento do T. paradoxa, mas, foi menos eficiente

1 Ciências Biológicas; Universidade do Sagrado Coração; E-mail: mts.np99@gmail.com

2 Ciências Biológicas; Universidade do Sagrado Coração; e-mail: cbrafae107@hotmail.com

3 Dra.; Agronomia; Universidade Estadual Paulista Júlio de Mesquita Filho, UNESP, Brasil; Atua nos seguintes temas: Fungos fitopatogênicos biotróficos, manejo de culturas, solarização e microbiologia de solos; Endereço: Secretaria de Agricultura e Abastecimento, Agência Paulista de Tecnologia do Agronegócio - APTA, DDD. Avenida Rodrigues Alves, 40-40, Vila Cardia. CEP:17030000 - Bauru, SP - Brasil; E-Mail: cruzjcs@apta.sp.gov.br

4 Dra.; Agronomia; Universidade Estadual Paulista Júlio de Mesquita Filho, UNESP, Brasil; Experiência na área de Microbiologia, com ênfase em Tecnologia de Cultivo de Cogumelos Comestíveis; Endereço: Faculdade Gran Tietê. Av. XV de novembro, 125, Centro. CEP:17340000 - Barra Bonita, SP - Brasil; E-Mail: mcnandrade@hotmail.com (*) Autor para correspondências

\begin{tabular}{llllll}
\hline Ambiência & Guarapuava (PR) & v.l4 n.3 & p.5I3 - 52I & Set/Dez 2018 & ISSN I808 - 025I
\end{tabular}


se comparado aos demais óleos essenciais testados e ao fungicida. Assim, concluiu-se que, dentro das condições testadas, todos os óleos essenciais podem ser utilizados para inibir o crescimento do T.paradoxa, em especial Hortelã pimenta, Capim limão e Manjericão.

Palavras-chave: Inibição, fungos, cana-de-açúcar.

\section{Abstract}

Sugar cane plays an essential role in the Brazilian economy nowadays. However, sugar cane plantations are exposed to contamination by fungi like Thielaviopsis paradoxa, which is a causing pathogen of the pineapple disease. The use of essential oils is among the possible control methods of this disease. These oils are volatile, usually liquid and odoriferous substances extracted from the secondary metabolism of vegetables that may be used as antifungals, inseticides and bactericides. Therefore, the objective of the present study was to test the effect of essential oils on the control of T. paradoxa, thus allowing an economical and simple treatment which is harmless to both sugar cane plantation worker's and consumer's health. The experiment was carried out in a totally randomized design following the $4 \times 3$ factorial scheme (4 types of essential oils $\mathrm{x} 3$ concentrations), with 4 repetitions. Two witnesses (BDA culture medium not added with essential oil and added with the Pyraclostrobin fungicide, with 4 repetitions each) were also conducted with the treatments, totalizing 56 experimental units. The following essential oils were tested in the in vitro mycelial growth of the $T$. paradoxa fungus: carnation sheet (Eugenea caryophyllus), peppermint (Mentha piperita), lemongrass (Cymbopogon citratus) and basil (Ocimum basilicun), in the concentrations of $0.25 \%, 0.50 \%$ and $0.75 \%$. Peppermint, lemon grass and basil essential oils inhibited the mycelial growth by $100 \%$ in all the concentrations tested and they were as efficient as the generally used Pyraclostrobin fungicide. The treatment with carnation leaf also inhibited the growth of T.paradoxa, but it was less efficient, in comparison to the other essential oils tested and the fungicide. Thus, we concluded that all the essential oils may be used to inhibit the growth of T. paradoxa within the conditions tested, especially peppermint, lemon grass and basil.

Keywords: inhibition, fungi, sugar cane.

\section{Introdução}

Historicamente, a cana-de-açúcar sempre teve um importante papel na economia do país. Começou no século XVI com o processo de fabricação do açúcar nos engenhos, depois, com um maior conhecimento e novas técnicas na fabricação de bebidas e até perfumes. Atualmente, tem grande utilidade na obtenção do etanol que é um combustível que causa menos danos ao ambiente, é mais barato e renovável (FERREIRA, et al., 2008).

Os canaviais estão expostos a prejuízos indiretos, os quais são provocados pela entrada do fungo Thielaviopsis paradoxa. Este patógeno causador da podridão abacaxi é incapaz de penetrar por seus próprios meios em tecidos íntegros ou por aberturas naturais da planta, somente por ferimentos. $\mathrm{Na}$ cana-de-açúcar, isso é particularmente importante, porque o corte das mudas em toletes para o plantio oferece uma porta de entrada ao fungo. Em toletes infectados, o 
desenvolvimento de raízes e gemas é retardado e inibido, e, em geral, os brotos morrem antes de emergirem do solo ou competirem com plantas vizinhas. Os fungos são responsáveis por $70 \%$ das doenças que causam danos em várias culturas, reduzindo a produtividade e podendo acabar com plantações inteiras acarretando em grandes prejuízos econômicos para as empresas do ramo e para o país (CHAPOLA et al., 2014).

A podridão abacaxi da cana-de-açúcar, causada pelo fungo T. paradoxa, fase assexuada de Ceratocystis paradoxa, pode reduzir em até $50 \%$ a brotação e em até $42 \%$ a produtividade de colmos. O patógeno está presente no solo e infecta a cana-de-açúcar logo após o plantio (BEGUM et al. 2008 apud CHAPOLLA et al., 2014).

Os métodos mais utilizados no controle do T. paradoxa são fungicidas químicos e algumas práticas culturais. A estratégia mais largamente utilizada para o manejo de doenças é o uso de variedades de plantas resistentes. Porém, para algumas variedades ou doenças, isso ainda não é disponível ou eficaz e exige outros métodos de controle. $\mathrm{O}$ uso de produtos ou métodos de aplicação de maneira descuidada ou indiscriminada pode causar prejuízos financeiros e ecológicos, requerendo critérios quando de sua utilização (FERREIRA et al., 2008).

Os óleos essenciais são substâncias voláteis, geralmente líquidas e odoríferas extraídas do metabolismo secundário de vegetais os quais podem ser usados como antifúngicos, inseticidas e antibactericidas. Para serem produzidos e comercializados corretamente devem vir de fontes renováveis, desde a sua plantação, colheita e extração. Incluem ainda, fatores climáticos e externos como a escassez de matérias primas, tipo de armazenamento, de embalagem, de transporte para preservação da sua qualidade e manter as propriedades terapêuticas da planta de origem. Eles podem ser uma boa opção para combater o T. paradoxa, pois, em várias pesquisas, o uso de óleos essenciais extraídos de plantas aromáticas no controle antifúngico tem se demonstrado eficiente, atuando como um fungicida natural (CHAPOLA et al., 2014), sendo assim, uma alternativa mais simples, econômica e não tóxica, tanto para o ambiente quanto para a saúde do trabalhador que lida com os produtos tóxicos no combate aos fungos. Também torna o alimento mais atraente ao consumidor, proporcionando benefícios a saúde (PEREIRA et al., 2006).

Vários estudos têm comprovado o efeito de compostos isolados extraídos de óleos essenciais de plantas que atuam como fungicidas naturais inibindo a atividade fúngica e, um número significativo destes constituintes tem se mostrado eficaz (PEREIRA et al., 2006). Entre estes, o cravo folha (Eugenea caryophyllus) contém alto teor de eugenol, substância que apresenta uma elevada atividade anestésica (RODRIGUES et al., 2012). O de hortelã pimenta (Menthapiperita) contém alto teor de mentol, mentona e mentofurano, substâncias que apresentam uma elevada atividade antibacteriana (ALVES et al., 2010). O capim-limão (Cymbopogon citratus) contém alto teor de citral e limoneno, substâncias que apresentam uma elevada atividade fungicida. $\mathrm{O}$ manjericão (Ocimum basilicun) contém alto teor de linalol, substância que apresenta uma elevada atividade antisséptica (PRAVUSCHI et al., 2010).

Embora sejam escassos os relatos de óleos vegetais inibindo o crescimento micelial de Thielaviopsis sp., há diversos trabalhos em outros patossistemas (NASCIMENTO et al., 2013). Assim, o estudo da podridão abacaxi, causada pelo fungo T. paradoxa, bem como das técnicas eficazes para o seu controle são muito importantes. Neste sentido, o controle alternativo com a utilização de óleos essenciais apresenta-se como opção ao manejo integrado de doenças em função do menor risco ambiental e custo reduzido. 
Portanto, o objetivo deste trabalho foi testar o efeito dos óleos essenciais de hortelã pimenta (Mentha piperita); de manjericão (Ocimum basilicun); de capim-limão (Cymbopogon citratus) e de cravo folha (Eugenea caryophyllus) no controle do T. paradoxa.

\section{Material e Métodos}

O experimento foi desenvolvido no Laboratório de Biologia da Universidade do Sagrado Coração, Bauru, SP. Foi avaliado o efeito in vitro dos óleos essenciais, em diferentes concentrações, sobre o T. paradoxa, cuja cultura foi fornecido pelo APTA (Agência Paulista de Tecnologia dos Agronegócios) de Bauru, SP. Para isso, foi avaliado o crescimento micelial deste fungo cultivado em meio de cultura BDA (batata-dextrose-ágar), acrescido dos seguintes óleos essenciais: manjericão (Ocimum basilicun); cravo folha (Eugenia caryophyllus); capim limão (Cymbopogon citratus) e hortelã pimenta (Mentha piperita) (Figura 1), os quais foram comprados da empresa Terra Flor Aromaterapia. Todos os óleos foram testados nas concentrações 0,25\%,0,5\% e 0,75\%. Também foi conduzida juntamente com os tratamentos duas testemunhas (meio de cultura BDA sem adição de óleo essencial e com adição do fungicida Piraclostrobina ${ }^{1}$, cada um com 4 repetições), totalizando 56 unidades experimentais.

\section{Figura 1- Óleos essenciais testados na experimentação.}

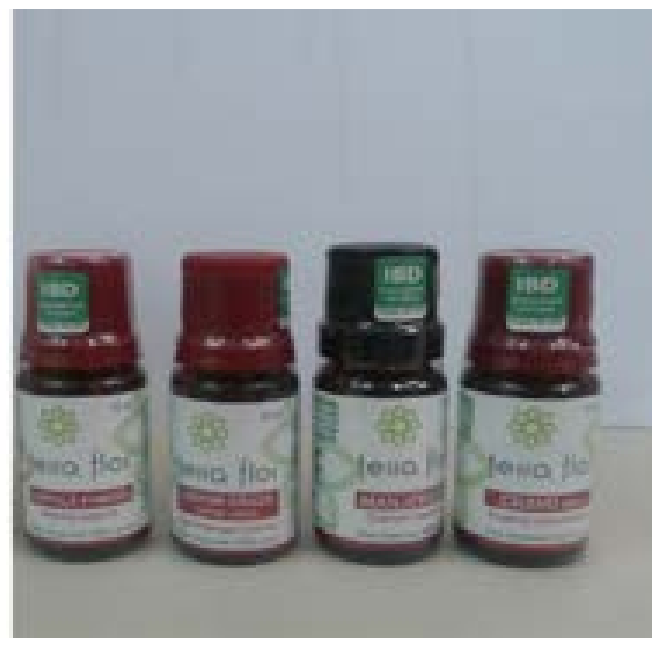

Fonte: Autoria própria.

O experimento foi conduzido no delineamento inteiramente casualizado segundo o esquema fatorial 4 × 3 (4 tipos de óleos essenciais x 3 concentrações), totalizando 12 tratamentos, cada qual com 4 repetições.

O isolado de T. paradoxa, proveniente da coleção da Agência Paulista de Tecnologia dos Agronegócios (APTA) de Bauru, SP, foi cultivado em placa de Petri contendo o meio BatataDextrose-Ágar (BDA) (Figura 2). Após sete dias de incubação a $25^{\circ} \mathrm{C}$ na câmara BOD discos de $0,5 \mathrm{~cm}$ foram retirados da periferia da colônia fúngica e transferidos para as placas com os tratamentos, servindo assim como inóculo. 
Figura 2- Cultura de Thielaviopsis paradoxa utilizada como inóculo.

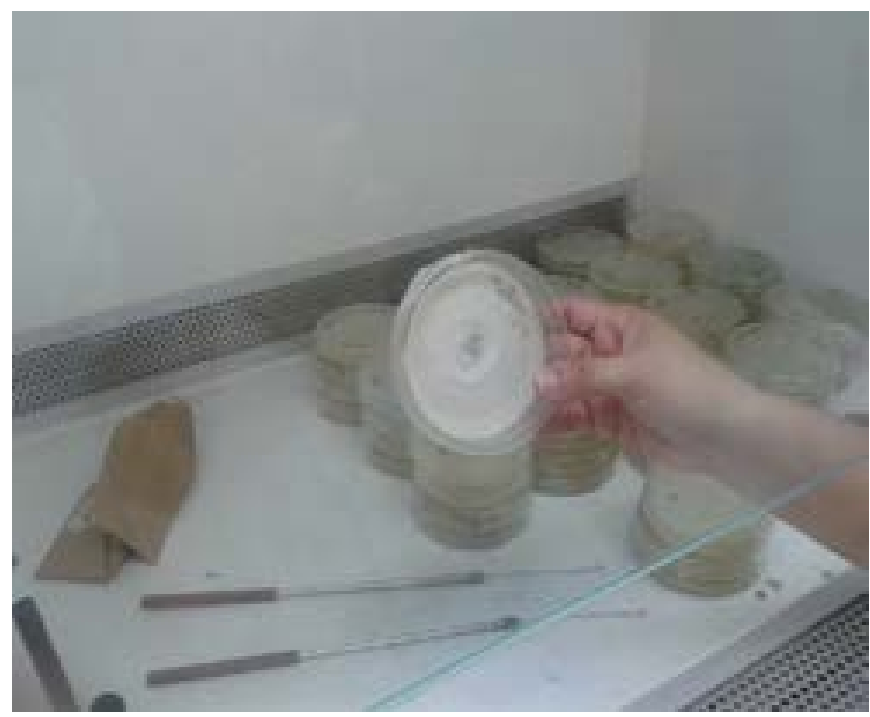

Fonte: Autoria própria.

Os óleos essenciais foram adicionados ao meio de cultura no momento destes serem vertidos nas placas nas concentrações já citadas (Figura 3). Após a solidificação do meio, discos de 0,5 $\mathrm{cm}$ foram retirados da colônia fúngica e transferidos para as placas de Petri com os tratamentos (Figura 4). As placas ficaram mantidas em câmaras BOD a 25 C, sendo distribuídas inteiramente ao acaso.

Figura 3- Adição de óleo essencial ao meio de cultura.

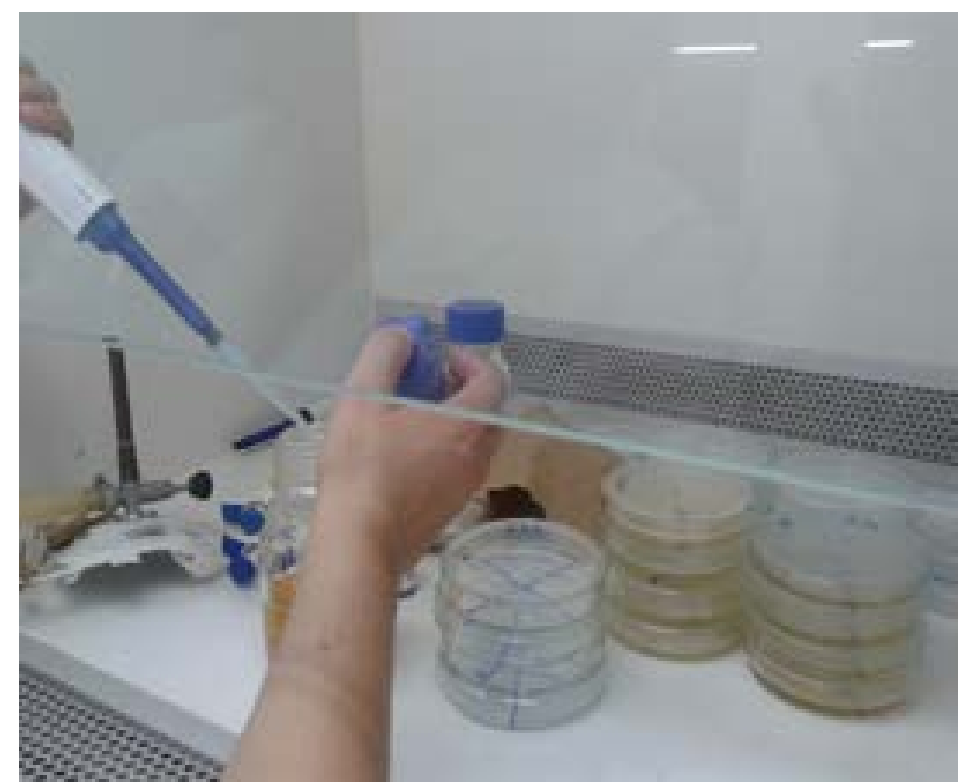

Fonte: Autoria própria. 


\section{Figura 4- Inoculação da colônia fúngica na placa com tratamento.}

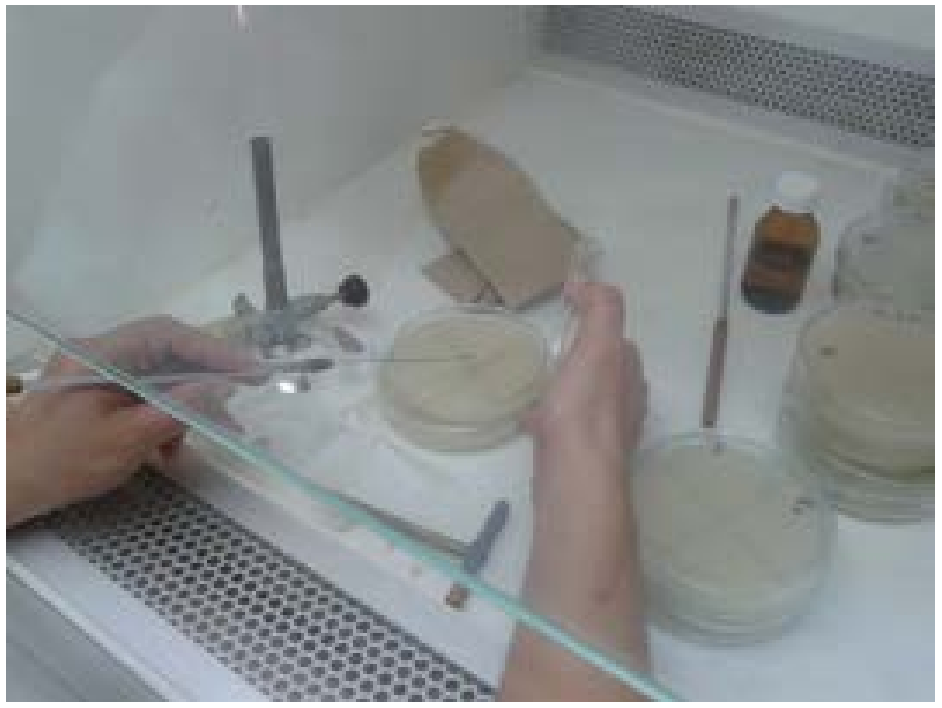

Fonte: Autoria própria.

O crescimento micelial foi acompanhado diariamente (a cada 24 horas) analisando o limite de crescimento do fungo, através de marcações no fundo nas placas com canetas de retroprojetor de diferentes cores e com a ajuda de um contador de colônias para facilitar a visualização do halo de crescimento (Figura 5). Esta avaliação deu-se até que a primeira colônia da testemunha com BDA puro atingisse a borda da placa de Petri (crescimento máximo). Em seguida, mensurouse o diâmetro das colônias $(\mathrm{cm})$, com um paquímetro digital em todos os tratamentos em duas posições perpendiculares entre si, considerando o valor médio das medidas. $\mathrm{Na}$ análise estatística foi utilizado o teste de Tukey no intuito de verificar se as médias de crescimento micelial apresentadas eram distintas.

\section{Figura 5- Marcação do crescimento micelial.}

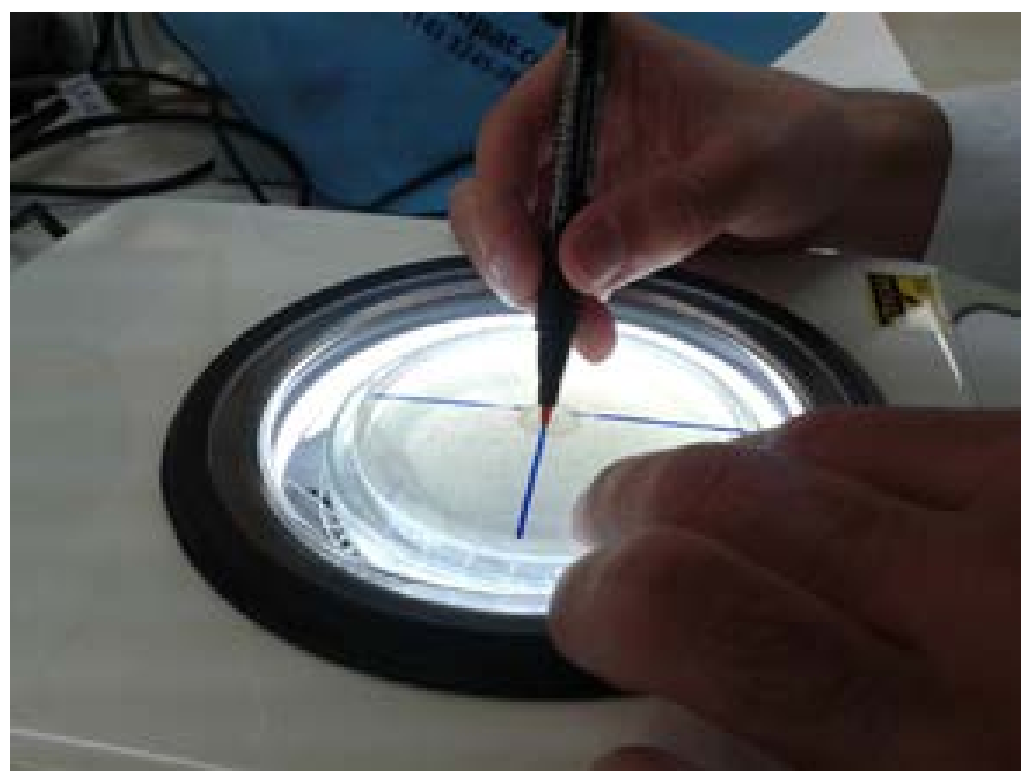

Fonte: Autoria própria. 


\section{Resultados e discussão}

Os óleos essenciais de capim-limão, manjericão e hortelã pimenta inibiram em 100\% o crescimento micelial do T. paradoxa em todas as concentrações testadas (Tabela 1) sendo, estatisticamente, tão eficientes quanto o fungicida Piraclostrobina. O Cravo folha, embora também tenha inibido o crescimento do T. paradoxa, foi menos eficiente do que os demais óleos essenciais testados e o fungicida (Tabela 1 ).

Os resultados obtidos no presente trabalho, em relação ao óleo essencial de capim limão (Cymbopogon citratus), vão ao encontro dos resultados obtidos por Santos (2014) em seu trabalho, ou seja, $100 \%$ de inibição do crescimento micelial do Phomopsis sojae. Também é possível notar, em outros trabalhos como de Sarmento-Brum et al. (2013), a inibição total de outros fungos pela ação do mesmo óleo. Esses trabalhos reforçam e comprovam a potencialidade dele como fungicida natural.

Outro óleo que também obteve resultados satisfatórios foi o de manjericão (Ocimum basilicun), inibindo o crescimento micelial totalmente em todas as concentrações assim como em Santos (2014). Já, em Pereira et al.(2006), a inibição foi parcial em três dos quatros fungos testados levantando assim a hipótese de que o óleo tenha poder inibitório variado dependendo do fungo e da concentração utilizadas. Nesse trabalho com o T. paradoxa o óleo de manjericão apresentou ótimos resultados em todas as concentrações testadas.

O óleo de hortelã pimenta (Mentha piperita), em Lorenzetti et al. (2011), apresentou resultados satisfatórios inibindo em $96 \%$ o crescimento do fungo Botrytis cinerea em relação à testemunha. Nessa pesquisa, o poder inibitório do óleo foi maior, tendo inibido o crescimento do T. paradoxa em 100\%, assim como no experimento realizado por Nascimento (2013) com o mesmo fungo. Em Pereira et al. (2006), o poder inibitório da hortelã pimenta não foi tão efetivo, apresentando resultados variados no crescimento dos fungos testados, podendo ter como justificativa as baixas concentrações utilizadas no teste.

\section{Tabela 1- Crescimento micelial $(\mathrm{mm})$ de Thielaviopsis paradoxa em meios de cultura adicionados de óleos essenciais em diferentes concentrações após 72 horas de inoculação a $25^{\circ} \mathrm{C}$.}

\begin{tabular}{cc}
\hline Tratamentos & $\begin{array}{c}\text { Crescimento micelial } \\
(\mathbf{m m})\end{array}$ \\
\hline BDA** $^{* *}$ & $78,50 \mathrm{~A}^{*}$ \\
Cravo folha 0,75 & $8,25 \mathrm{~B}$ \\
Cravo folha 0,50 & $8,00 \mathrm{~B}$ \\
Cravo folha 0,25 & $7,00 \mathrm{~B}$ \\
Fungicida** & $1,50 \mathrm{C}$ \\
Capim limão 0,75 & $0,00 \mathrm{C}$ \\
Capim limão 0,50 & $0,00 \mathrm{C}$ \\
Capim limão 0,25 & $0,00 \mathrm{C}$ \\
Manjericão 0,75 & $0,00 \mathrm{C}$ \\
Manjericão 0,50 & $0,00 \mathrm{C}$ \\
Manjericão 0,25 & $0,00 \mathrm{C}$ \\
Hortelã pimenta 0,75 & $0,00 \mathrm{C}$ \\
Hortelã pimenta 0,50 & $0,00 \mathrm{C}$ \\
Hortelã pimenta 0,25 & $0,00 \mathrm{C}$ \\
\hline
\end{tabular}

Fonte: Elaborada pelo autor.

${ }^{*}$ Médias seguidas de letras iguais não diferem estatisticamente entre si pelo teste de Tukey $(p<0,05)$. CV (\%) $=28,53$.

${ }^{* *} B D A$ e o fungicida Piraclostrobina foram utilizados como testemunhas. 
No presente experimento, dentre os óleos essenciais testados, o cravo folha (Eugenea caryophyllus) foi o menos efetivo, diferentemente de Santos (2014), que obteve inibição total do crescimento do fungo Phomopsis sojae submetido às mesmas concentrações do óleo. Rodrigues (2012) também obteve bons resultados na inibição de crescimento fúngico em suas pesquisas com este óleo, podendo-se, assim, levantar a hipótese de que o fungo T. paradoxa seja resistente às concentrações testadas, sendo necessário, em futuros estudos, usar doses maiores de cravo folha.

\section{Conclusão}

Os óleos essenciais de Hortelã pimenta, Capim limão e Manjericão foram tão eficientes quanto o fungicida testado, apresentando uma opção para o controle da podridão abacaxi causada pelo T. paradoxa. No entanto, novas pesquisas devem ser avaliadas para que a sua aplicação no campo possa ser testada.

\section{Referências}

ALVES, L. A; FREIRES, I. A; CASTRO, R. D. Efeito antibacteriano de óleos essenciais sobre bactérias formadoras do biofilme dentário. Revista Brasileira de Ciências da Saúde, UFPB, v. 14, n. 2, p. 57-62, 2010. Disponível em:< http://periodicos.ufpb.br/ojs/index. php/rbcs/article/view/7354/5308 >. Acesso em: 16 out. 2014.

HAPOLA, R. G.; OGASAWARA, G. A.; JANS, B.; MASSOLA JUNIOR, N. S. Controle da podridão abacaxi da cana-de-açúcar por meio da pulverização de fungicidas em rebolos no sulco de plantio. Ciência Rural, Santa Maria, v.44, n.2, p.197-202, fev. 2014. Disponível em: <http://www.scielo.br/pdf/cr/v44n2/a4014cr2013-0418.pdf $>$. Acesso em: 04 abr. 2014.

FERREIRA,M.C.; WERNECK, C. F.; FURUHASHI, S.; LEITE, G.J. Tratamento de toletes de cana-de-açúcar para controle da podridão-abacaxi em pulverização conjugada ao plantio mecanizado. Revista Engenharia Agrícola, Jaboticabal, v.28, n.2, p.263-273, abr-jun. 2008. Disponível em:< http://www.scielo.br/pdf/eagri/v28n2/a07v28n2.pdf $>$. Acesso em: 04 abr. 2014.

LORENZETTI, E.R.; MONTEIRO, F. P.; SOUZA, P. E.; SOUZA, R. J; SCALICE, H. K., DIOGO JR, R.; PIRES, M. S. O. Bioatividade de óleos essenciais no controle de Botrytis cinerea isolado de Morangueiro. Revista Brasileira de Plantas Medicinais, Botucatu, v.13, especial, p.619-627,2011. Disponível em:<http://www.scielo.br/pdf/rbpm/ v13nspe/a19v13nspe.pdf>. Acesso em: 04 abr. 2014.

NASCIMENTO, S. M. C.; CARVALHO, E. A.; WARWICK, D. R. N.; PALHETA, J. G.; SANTOS, T. P. F. Inibição do crescimento micelial de Thielaviopsis paradoxa por óleos vegetais. ENCONTRO AMAZÔNICO DE AGRÁRIAS, 5., 2013, Belém, PA. Anais eletrônicos... Belém, PA: UFRA, 2013. Disponível em: $<$ http://www.alice.cnptia. embrapa.br/handle/doc/979377>. Acesso em: 06 abr. 2014. 
PEREIRA, M. C.; VILELA, G. R.; COSTA, L. M. A. S., SILVA, R. F.; FERNANDES, A.F.; FONSECA, E.W.N.; PICCOLI, R.H. Inibição do desenvolvimento fúngico através da utilização de óleos essenciais de condimentos. Ciências e agrotecnologias, Lavras, v. 30, n. 4, p. 731-738, jul-ago. 2006. Disponível em: $<$ http://www.scielo.br/pdf/cagro/v30n4/ v30n4a20.pdf>. Acesso em: 04 abr. 2014.

PRAVUSCHI, P. R., MARQUES, P. A. A., RIGOLIN, B. H. M.; SANTOS, A. C. P. Efeito de diferentes lâminas de irrigação na produção de óleo essencial do manjericão (Ocimum basilicum L.).Acta Scientiarium Agronomy, Maringá v. 32, n. 4, p. 687-693, outdez. 2010. Disponível em:< http://dx.doi.org/10.4025/actasciagron.v32i4.3160>. Acesso em: 31 ago. 2014.

RODRIGUES, M. L. Uso de óleos essenciais em frutos de bananeira no controle da antracnose "prata anâ". Unimontes, c2012. Disponível em: $<$ http://www.producaovegetal. com.br/arquivos upload/editor/file/dissertacao maria rodrigues.pdf $>$. Acesso em: 16 out. 2014.

SANTOS, P. L. Efeito de óleos essenciais sobre o fungo Phomopsis sojae e a qualidade fisiológica de sementes de soja. Unesp.com, 2014. Disponível em:<http://www.pg.fca. unesp.br/Teses/PDFs/Arq1071.pdf>. Acesso em: 06 abr. 2014.

SARMENTO-BRUM. R. B. C.; SANTOS, G. R.; CASTRO, H. G.; GONÇALVES, C. G.; CHAGAS JÚNIOR, A. F.; NASCIMENTO, I. R. Efeito de óleos essenciais de plantas medicinais sobre a antracnose do sorgo. Bioscience Journal, Uberlândia, v. 29, suplemento 1, p. 1549-1557, nov. 2013. Disponível em:< http://www.seer.ufu.br/index. php/biosciencejournal/article/view/15229/13301>. Acesso em: 16 out. 2014. 